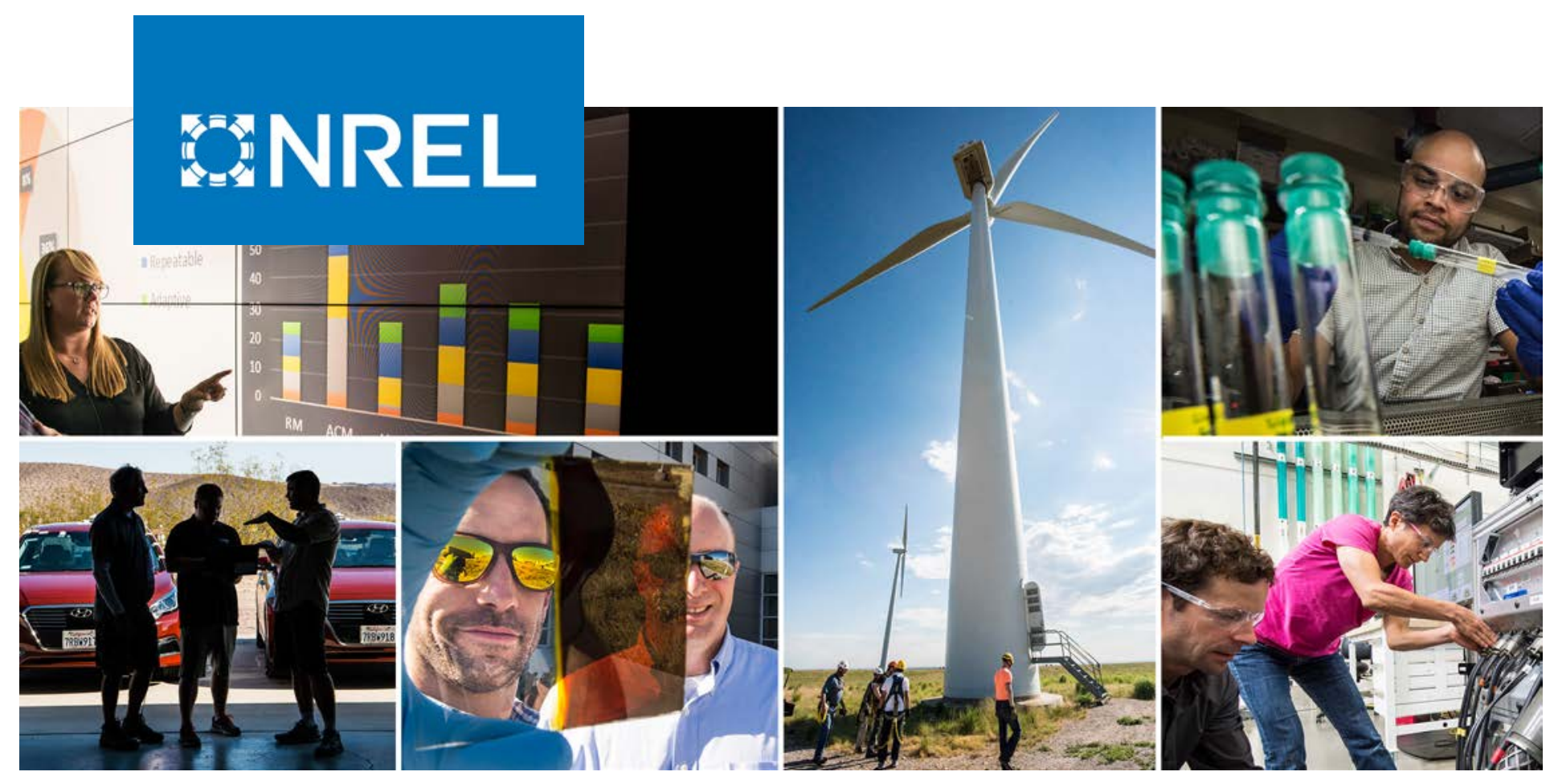

\title{
Model of Operation-and-Maintenance Costs for Photovoltaic Systems
}

Andy Walker, ${ }^{1}$ Eric Lockhart, ${ }^{1}$ Jal Desai, ${ }^{1}$ Kristen Ardani, ${ }^{1}$ Geoff Klise, ${ }^{2}$ Olga Lavrova, ${ }^{2}$ Tom Tansy, ${ }^{3}$ Jessie Deot, ${ }^{3}$ Bob Fox, ${ }^{3}$ and Anil Pochiraju ${ }^{3}$

${ }^{1}$ National Renewable Energy Laboratory

${ }^{2}$ Sandia National Laboratories

${ }^{3}$ SunSpec Alliance

NREL is a national laboratory of the U.S. Department of Energy Office of Energy Efficiency \& Renewable Energy

Operated by the Alliance for Sustainable Energy, LLC

This report is available at no cost from the National Renewable Energy Laboratory (NREL) at www.nrel.gov/publications.
Technical Report

NREL/TP-5C00-74840

June 2020 


\title{
GNREL
}

\section{Model of Operation-and-Maintenance Costs for Photovoltaic Systems}

\author{
Andy Walker, ${ }^{1}$ Eric Lockhart, ${ }^{1}$ Jal Desai, ${ }^{1}$ Kristen Ardani, ${ }^{1}$ \\ Geoff Klise, ${ }^{2}$ Olga Lavrova, ${ }^{2}$ Tom Tansy, ${ }^{3}$ Jessie Deot, ${ }^{3}$ \\ Bob Fox, ${ }^{3}$ and Anil Pochiraju \\ ${ }^{1}$ National Renewable Energy Laboratory \\ ${ }^{2}$ Sandia National Laboratories \\ ${ }^{3}$ SunSpec Alliance
}

\section{Suggested Citation}

Walker, Andy, Eric Lockhart, Jal Desai, Kristen Ardani, Geoff Klise, Olga Lavrova, Tom Tansy, Jessie Deot, Bob Fox, and Anil Pochiraju. 2020. Model of Operation-andMaintenance Costs for Photovoltaic Systems. Golden, CO: National Renewable Energy Laboratory. NREL/TP-5C00-74840. https://www.nrel.gov/docs/fy20osti/74840.pdf.

NREL is a national laboratory of the U.S. Department of Energy Office of Energy Efficiency \& Renewable Energy Operated by the Alliance for Sustainable Energy, LLC

This report is available at no cost from the National Renewable Energy Laboratory (NREL) at www.nrel.gov/publications.

Contract No. DE-AC36-08GO28308
Technical Report NREL/TP-5C00-74840 June 2020

National Renewable Energy Laboratory 15013 Denver West Parkway Golden, CO 80401 303-275-3000 • www.nrel.gov 


\section{NOTICE}

This work was authored in part by the National Renewable Energy Laboratory, operated by Alliance for Sustainable Energy, LLC, for the U.S. Department of Energy (DOE) under Contract No. DE-AC36-08GO28308. Funding provided by U.S. Department of Energy Office of Energy Efficiency and Renewable Energy (EERE) under Solar Energy Technologies Office (SETO) Agreement Number 32315. The views expressed herein do not necessarily represent the views of the DOE or the U.S. Government.

This report is available at no cost from the National Renewable Energy Laboratory (NREL) at www.nrel.gov/publications.

U.S. Department of Energy (DOE) reports produced after 1991 and a growing number of pre-1991 documents are available free via www.OSTI.gov.

Cover Photos by Dennis Schroeder: (clockwise, left to right) NREL 51934, NREL 45897, NREL 42160, NREL 45891, NREL 48097, NREL 46526

NREL prints on paper that contains recycled content. 


\section{Acknowledgments}

This work was funded by the U.S. Department of Energy (DOE) Solar Energy Technology Office (SETO) under Agreement \#32315, "Best Practices for Installation, Operation and Maintenance of Photovoltaics and Storage Systems," October 2016-September 2018. The program manager is Ammar Qusaibaty, and previously was Christine Nichols. Hilary HatchCopeland and Katie Wensuc of the National Renewable Energy Laboratory (NREL) edited this report. 


\section{List of Acronyms}

$\alpha$

AD

$\beta$

d

DOE

$\mathrm{g}$

i

k

$\mathrm{kW}$

$\mathrm{kWh}$

LBNL

LCOE

MW

$\mathrm{N}$

$\mathrm{n} / \mathrm{N}$

NREL

O\&M

$\mathrm{P}$

PV

PVROM

Q

$\mathrm{R}_{\text {desired }}$

SETO

SNL

$\mathrm{T}$

WACC

$\mathrm{Y}$
Shape factor of Weibull distribution indicating how spread out the probability of failure is over the years, obtained from heuristic failure data. Anderson Darling

Scale factor of Weibull distribution indicating over which years of the analysis period the bulk of the failure distribution lies, obtained from heuristic failure data.

financial annual discount rate $(\% / y e a r)$

U.S. Department of Energy

annual degradation rate $(\% /$ year $)$ in system energy delivery

financial annual inflation rate (\%/year)

an index referring to the number of the term in a polynomial expansion

kilowatt, direct current (DC) unless specified alternating current (AC)

kilowatt hour

Lawrence Berkeley National Laboratory

levelized cost of energy

megawatt

number of a certain type of component (for example $\mathrm{N}=10$ inverters, $\mathrm{N}=$ 500 combiner boxes, or $\mathrm{N}=50,000 \mathrm{PV}$ modules)

Fraction of total number of a specific type of component covered by reserve account in order to achieve desired probability that reserve account will be sufficient in a given year.

National Renewable Energy Laboratory

operation and maintenance

Probability that a component will not fail in any given year, specific to that year only, according to the statistical distribution of component failure.

photovoltaic

PV Reliability Operations and Maintenance database

probability that a component will fail in a year, $\mathrm{Q}=1-\mathrm{P}$

desired probability (or percentage) that the reserve account will be

sufficient to pay for required replacements in that year

Solar Energy Technologies Office

Sandia National Laboratories

duration of the analysis period

weighted-average cost of capital

year of the analysis period (Year 1, Year 2, and so on) 


\section{Executive Summary}

This report presents a method for calculating costs associated with the operation and maintenance (O\&M) of photovoltaic (PV) systems. The report compiles details regarding the cost and frequency of multiple O\&M services to estimate annual O\&M costs (\$/year) for each year of an analysis period, the net present value (\$) of life cycle costs accumulated over the analysis period, and the reserve account amount (\$) that might be required to fund unexpected repairs. The reserve account includes parts inventory and is important for providing a source of funds to make repairs quickly and avoid lost production. This method allows a detailed selection of services to perform based on system size, market served (e.g., residential, commercial, or utility), type and configuration of system components (e.g., micro-, string, or central inverter), and site and environmental conditions (e.g., pollen, bird populations) which is an improvement over simple per unit valuations of O\&M costs $(\$ / \mathrm{kW} /$ year). This model also distinguishes costs that vary from year to year and increase at different rates over time as modeled by heuristic failure distributions (e.g., Weibull or Lognormal distribution) based on actuarial data for many of the services. This cost model was created with input from the PV O\&M Working Group of researchers and industry, sponsored by U.S. Department of Energy (DOE) Solar Energy Technologies Office (SETO) 2016-2018. The PV O\&M Cost model was developed initially as a Microsoft Excel spreadsheet and subsequently published as an on-line application by Sunspec Alliance at apsuite.sunspec.org (Contact the NREL authors for the spreadsheet version). AP Suite stands for Asset Performance Suite and includes both the PV O\&M Cost Model and Open System Performance and Reliability Clearinghouse (oSPARC), which logs system performance. 


\section{Table of Contents}

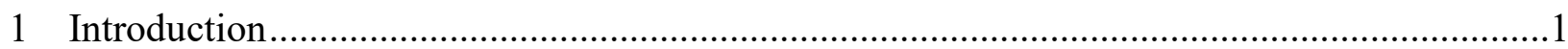

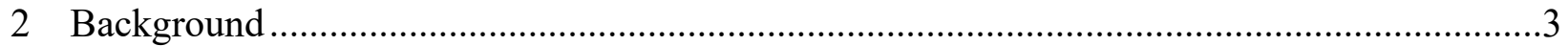

3 Failure Probability Density Function for Each Component ……...........................................

3.1 Heuristic Data to Inform Failure Probability Distributions............................................5

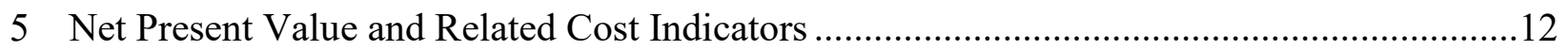

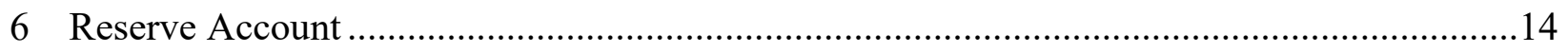

6.1 Example of Reserve Account Calculation (10 Components)........................................16

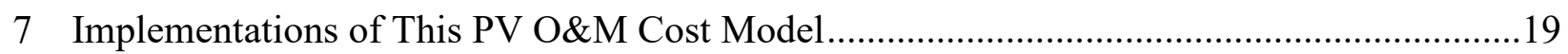

7.1 Pilot Implementation in Spreadsheet Program ........................................................19

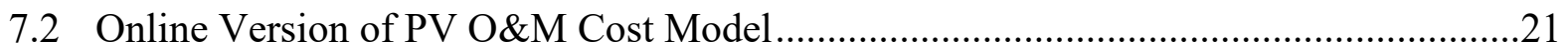

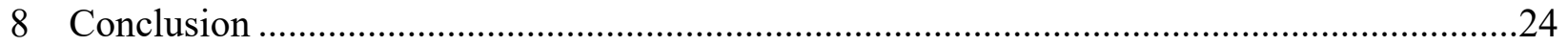

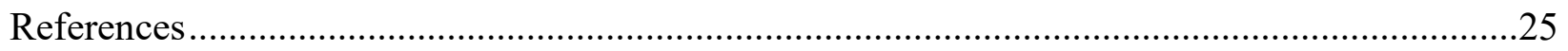




\section{List of Figures}

Figure 1. Example calculation of failure distribution parameters from raw event data (failure and repair data)

Figure 2. Flowchart for calculation of annual cost (\$/year) for each service and year of analysis

period

Figure 3. Illustration of how annual cash flows are calculated considering an example of replacement costing $\$ 10,000$. a) $\$ 10,000$ O\&M cost would be escalated according to inflation; b) the replacement cost is multiplied by the failure probability to provide the cash flows modified by failure probability distribution; c) each year's cash flow is modified by logic related to warranty and analysis periods; and d) each year of future cost is discounted to present value and summed for net present value.

Figure 4. Chart of probability that reserve account will be sufficient as a function of fraction of total number of component in reserve, and for different values of failure probability

Figure 5. Flowchart for calculation of reserve account associated with each service and each year

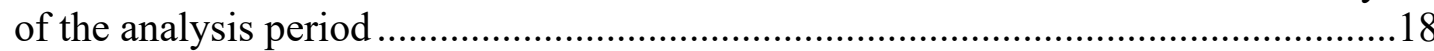

Figure 6. Partial list of inputs for spreadsheet deployment of PV O\&M cost model, with an example of a 10-MW ground-mounted PV system ................................................20

Figure 7. Example report from PV O\&M cost model for 1-MW ground-mounted system ..........21

Figure 8. Beginning of data input sheets for online version of PV O\&M cost model, available at

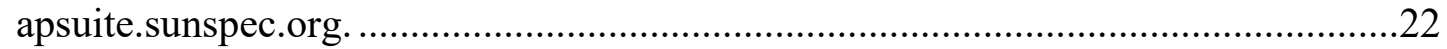

Figure 9. Sample report from online version of PV O\&M cost model, showing annual O\&M costs, net present value, and reserve account amount for each year of the analysis period, and key indicators such as $\$ / \mathrm{kW} /$ year and $\$ / \mathrm{kWh}$ delivered.

\section{List of Tables}

Table 1. Example of the Weibull Shape, $\alpha$, and Scale, $\beta$, Factors for Selected Service Measures.............. 7

Table 2. Inputs and Outputs of "Reserve Account" Calculation 


\section{Introduction}

This report describes both mathematical derivation and the resulting software for a model to estimate operation and maintenance (O\&M) costs related to photovoltaic (PV) systems. The cost model estimates annual cost by adding up many services assigned or calculated for each year. The PV O\&M cost model assumptions and modeled cost drivers represent dependencies on system size and type, site and environmental conditions, and age. Also, a detailed cost model allows investigation of how costs change over a very long performance period.

O\&M services in the cost model correlate to the PV O\&M services described in Appendix B and Appendix C of Best Practices for Operations and Maintenance of Photovoltaic and Energy Storage Systems; 3rd Edition (see https://www.nrel.gov/docs/fy19osti/73822.pdf), prepared by a group of industry professionals convened by the National Renewable Energy Laboratory (NREL), Sandia National Laboratories (SNL), SunSpec Alliance, and Roger Hill, and sponsored by the U.S. Department of Energy (DOE) Solar Energy Technologies Office (SETO). This SETO effort also includes the collection of actuarial data (failure and repair data) by the SNL PV Reliability Operations and Maintenance (PVROM) database (Klise et al. 2018) to inform how often corrective services are performed.

This report describes the form of the model, but values assigned to the cost of each measure (labor rates and material costs) or values for economic parameters such as inflation rates should be provided by the user. The default labor and materials costs appearing in the model reflect the best judgment of the working group members that contributed information but should be considered placeholder values that the user should inspect and adjust. The model's form and parameters concentrates on three estimates related to the cost of delivering a PV O\&M program: annual O\&M costs (annual cash flow associated with O\&M), net present value of life cycle costs, and reserve account for timely repair of unplanned failures.

1. Annual O\&M Costs: Costs for administrative or preventive maintenance are scheduled on regular intervals. These costs are escalated according to an inflation rate to the year in which they occur. Costs for corrective maintenance are the replacement cost of the component multiplied by the probability that a failure will occur in that year. The resulting schedule of annual costs is in nominal dollars of the year that they occur, not real dollars referenced to the current year. The probability that a component will fail in any given year is calculated by a Weibull, log-normal, or other distribution, informed, ideally, by actuarial data. Warranties affect whether a failure will result in hardware costs, labor costs, or both, if the year is within the warranty period. This provides an annual cost (\$/year) for each year of an analysis period.

2. Net Present Value of Life Cycle Costs: The future years' cash flows calculated are then discounted to their present value according to a discount rate. The discount rate is the owner's time value of money. For federal agencies, this discount rate is published annually by the Applied Economics Office (Rushing et al. 2017) and is based on Treasury bill rates for an equivalent term (e.g., 20 years). Net present value is useful for evaluating an overall financial prospectus and for calculating the impact of O\&M on levelized cost of energy (LCOE). Each PV project might entail a weighted-average cost of capital (WACC) that blends the cost of debt and return on equity to calculate a net present value. The discount rate may be the WACC or might be a more general benchmark that the WACC is compared to, such as the corporate bond rate for a similar term. 
3. Reserve Account: The Weibull distribution of how failures are distributed over time leads to a good estimate of life cycle cost, but the method spreads the costs over the years and shows a rather uniform average cost per year-when, in fact, an expensive repair can occur all at once rather than distributed over multiple years Several years of low O\&M cost can be followed by a year of high cost. Financiers and operators want to know "maximum exposure"-in other words, what dollar amount of a reserve account or line of credit should an operator keep to cover higher-than-average annual costs? Reserve account is calculated for each year of the analysis period. 


\section{Background}

Costs to operate and maintain PV systems have been reported in terms of average annual cost on a per-unit basis, in units PV array capacity (direct current) of $\$ / \mathrm{kW} /$ year (Castillo-Ramírez et al. 2017; Brehaut 2016; EPRI and Sandia 2015; Barbose et al. 2017; GTM Research 2017; IRENA 2018; NREL 2018b; NREL 2018a; NREL; NREL/Sandia/SunSpec Alliance SuNLaMP, and PV O\&M Working Group 2016; Shimura et al. 2016). O\&M costs, on average, have been lowering over the years. For example, the Lawrence Berkeley National Laboratory (LBNL) reports O\&M costs for utility-scale systems are down from an average of $\$ 30 / \mathrm{kW} /$ year in 2011 to an average of $\$ 15 / \mathrm{kW} /$ year in 2015 , rebounding slightly to an average of $\$ 18 / \mathrm{kW} /$ year in 2017 (Bollinger 2017). In a more recent survey by LBNL (Wiser 2020) respondents divulged project-life assumptions increasing from an average of 21.5 years in 2007 to 32.5 years in 2019 and levelized, total lifetime operating expenses (O\&M, security, insurance, asset management) declining from an average of $\$ 35 / \mathrm{kW} / \mathrm{yr}$ in 2007 to an average of $\$ 17 / \mathrm{kW} / \mathrm{yr}$ in 2019 (Wiser 2020).

But a wide range is present in these reported costs within each year. For example, across 13 sources, the range in average total operating expense in 2019 is broad, from $\$ 13$ to $\$ 25 / \mathrm{kW} / \mathrm{yr}$ (Wiser 2020); in a previous report the O\&M costs for 2015 ranged from a minimum of $\$ 12 / \mathrm{kW} /$ year to a maximum of $\$ 30 / \mathrm{kW} /$ year (Bollinger 2017). Much of the variation in these per-kW costs is caused by differences in system scale ( $\mathrm{kW}$ or $\mathrm{MW}$ ); system configuration (roof or ground, tracking or fixed, central or string inverters); climate (temperature, snow); and site (urban or remote, dusty or unpolluted), making such averages unsuitable for estimating cost for any individual system. Further, costs to maintain a system change as the system ages (due to inflation, increasing failure rates, and expiring warranties), which is not informed by these averages.

Most PV plants have only been operational for a short amount of time-some $90 \%$ of PV plants globally have become commercially operable in the past 7 years, a relatively short period compared to their $20+$ year expected lifetime. The inadequacy of these heuristic data to estimate cost for a particular project highlights the importance of a bottom-up model for estimating future O\&M costs of PV systems. Also, many of these references exclude administrative costs, such as property taxes, insurance, land royalties, and other administrative costs. 


\section{$3 \quad$ Failure Probability Density Function for Each Component}

Many administrative costs, such as insurance payments, occur each year. Preventive maintenance costs are incurred according to a specified fixed interval that stipulates a service will be performed every 5 years, for example. But each of the corrective maintenance services depends on a failure pattern. The probability that a component will fail in the year under consideration (Q) is calculated according to a probability density function, where year is the only variable. The form of the failure probability density function for a component depends on the failure pattern of a component best represented by the distribution and mathematical constraints on evaluation of the distribution. One type of failure is not considered to affect another type of failure; each line item in the cost model is independent of the other line items. So in the current method, covariance is not addressed and is recommended as the topic of future investigation The method and software can accommodate any of five descriptions of the failure pattern: fixed-interval distribution, log-normal distribution, Weibull distribution, exponential distribution, and a combination of fixed interval and Weibull distributions, to model a "bathtub" distribution shape. A brief description and example failures for each distribution are provided below.

- Fixed Interval: A measure is preformed, and the resulting cost occurs according to a defined interval, such as every month, every year, or once every 5 years. For example, an O\&M cost estimate for a 5-MW ground-mounted system includes an annual insurance premium of $\$ 9,200$ and a cost of $\$ 4,500$ every 5 years for infrared inspection.

- Exponential: A component that fails following an exponential probability density function has a failure rate independent of previous or past years, and the curve has an exponential shape as the accumulated probability of failure approaches 1.0. This exponential shape typically occurs in what is called the useful life period after the early wear-out period. Examples include broken cover glass or inverter failures due to electronic components.

- Log-Normal: Failure occurs primarily because components wear out. A mathematical constraint is that the standard deviation of the lifetime must be less than half the mean lifetime. Examples include ultraviolet degradation of plastic parts and corrosion of metal parts.

- Weibull: Failure occurs primarily because one of two or more subcomponents wears out. Or failure is caused primarily by wear-out, but the standard deviation of the lifetime is so large as to preclude the use of the log-normal distribution. For example, an inverter may fail because of moisture that accumulates as a result of failed seals or overheating.

- Bathtub-Shaped Distribution: Manufacturing-related failures may be represented by a single probability in the first year and the remaining probability of wear-out failure in subsequent years with a Weibull or normal distribution. For example, PV modules not manufactured to specifications may fail in the first year, and, if not, later failures may occur because of wear-out.

The choice of which distribution function to use is described in Section 3.1. Default values in the PV O\&M cost model use the two-parameter Weibull distribution, due to the Weibull's flexibility in matching a wide range of data. The equation for the Weibull probability density function is presented in Equation 1 (Green and Bourne 1972): 
Equation 1

$$
Q=\frac{\alpha}{\beta^{\alpha}} y^{(\alpha-1)} e^{\left(\frac{-y}{\beta}\right)^{\alpha}}
$$

Where $\alpha=$ the "shape factor" of the distribution, indicating how spread out the probability of failure is over the years, and $\beta=$ the "scale factor" of the distribution, indicating over which years of the analysis period the bulk of the failure distribution lies. Q is the probability that a component will fail in the year under consideration. The parameters $\alpha$ and $\beta$ are obtained from heuristic failure data. In this PV O\&M Cost Model, these are provided by the PVROM database of failure and reliability data maintained by SNL. Measures for failure of PV modules, DC combiner, several inverter components, and transformers are informed by the PVROM data, while others are default values based on the authors' judgments with input and review by the aforementioned PV O\&M Working Group (Table 1). Best practice would be for a company to use its own collected actuarial data for a user's specific system and conditions, and to share these data to advance the art and science of estimating PV O\&M costs.

\subsection{Heuristic Data to Inform Failure Probability Distributions}

The actuarial data used to inform the probability distributions for many of the components (default values) were contributed by industry and compiled and summarized by SNL under this SETO-funded effort. SNL processed data from 244 systems, built 2013-2017, totaling over 600 MW of capacity (from the PVROM data). The PVROM data include 25 models of PV modules and 29 models of inverters, covering multiple equipment types and different geographic locations (Klise et al. 2018). Weibull failure distributions are listed in the Klise et al. (2018) report for PV modules, DC combiner, several inverter components, AC switchgear, transformer, grid interconnection, recloser, data-acquisition system, and programmable logic controller. Examples of select measures are also provided in Table 1. Based on the owner-provided data, inverter component failure modes with the greatest number of incidents observed over a 2.5-year period include: fan fault/failure, transistor failure, coolant flow/sensor faults, low voltage ride through, cycling faults, over voltage (DC side), common mode fault (DC side), and grid faults. These data represent fault codes that were first seen by the inverter, and the fault codes can be issues with the inverter, or near the combiner, strings, or modules, due to voltage or current issues that the inverter can detect when, for example, a string is disconnected. Preventive maintenance for inverters is also a key area of focus.

The methodology of identifying the right probability distribution function that fits the data is based on statistically validating failure probability distributions with time series data on component failures, based on goodness-of-fit tests (such as the chi-square test or KolmogorovSmirnov test) to check the validity of the assumed underlying failure distribution (Mood et al. 1974) and confidence intervals on variables, such as the mean lifetime of a component. This is known as the Reliability Performance Model and is described in Klise (2017) and previously in the user's manual for the System Advisor Model, found at: https://sam.nrel.gov/pvrpm. Often, processing the data to enable these calculations is a significant effort. Once the data has been processed and associated Time to Failure (TTF) and Time to Repair (TTR) values are calculated, goodness-of-fit data are applied to different distributions to determine which best represents the data. Typically, Weibull, log-normal, and exponential distributions are tried with the data. The 
most important statistics from the fitting process include the Anderson Darling (AD)-value (see https://prod-ng.sandia.gov/techlib-noauth/access-control.cgi/2018/181743.pdf) and P-value to determine statistical significance of the different distribution fits (an example is shown Figure 1). The determining factor is primarily a distribution that results in a low AD-value and high Pvalue, as shown graphically in Figure 1. Typically, for data used in this analysis, the Weibull is the best fit - due to its flexibility. For example, a Weibull with a shape factor (beta) of 1 is the same as an exponential distribution having a constant failure rate.

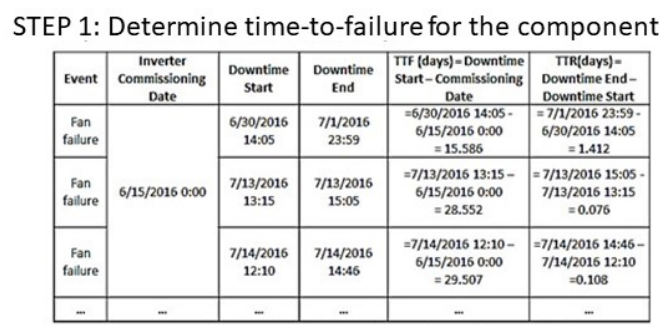

STEP 2: Compare fit of Normal, Lognormal, Exponential and Weibull distributions

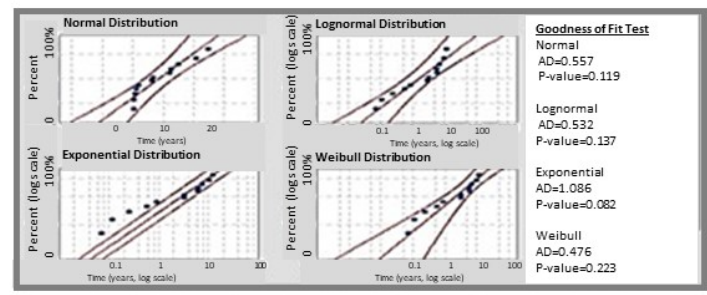

STEP 3: Best-fit probability distribution is used for "Failure Distribution"

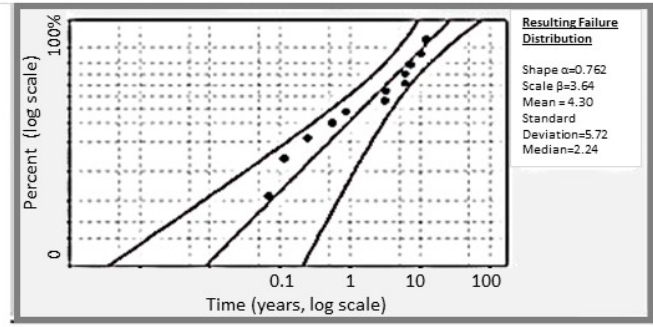

Figure 1. Example calculation of failure distribution parameters from raw event data (failure and repair data) for Inverter Fan Failure (all are 95\% confidence level, Klise et.al.2017)

Table 1 shows a failure distribution function Weibull shape, $\alpha$, and scale, $\beta$, factors for selected service measures from Klise et al. (2017). Depending on the number of records available, failure statistics can also be derived using a survival analysis approach. 
Table 1. Example of the Weibull Shape, $\alpha$, and Scale, $\beta$, Factors for Selected Service Measures

\begin{tabular}{|l|r|r|l|}
\hline Service Item & Weibull Shape Factor, $\boldsymbol{\alpha}$ & Weibull Scale Factor, $\boldsymbol{\beta}$ & Time Unit \\
\hline PV Module & 0.28 & $5 \mathrm{E} 12$ & Day \\
\hline Combiner Box & 0.51 & $1.2 \mathrm{E} 6$ & Day \\
\hline Inverter Fan & 0.760. & 3.64 & Year \\
\hline Inverter IGBT & 1.35 & 1.61 & Year \\
\hline AC Disconnect & 0.35 & 11,000 & Day \\
\hline Transformer & 0.88 & 7100 & Day \\
\hline Data Acquisition & 12.3 & 30338 & Hour \\
\hline
\end{tabular}

Source: Klise et al. 2017 


\section{Annual Cash Flow}

The PV O\&M Working Group developed a list of O\&M services (NREL 2018) that became the basis of the measures in the cost model. Each measure is described with a name; which categories of service it falls into; the type of labor needed to perform the service; equipment and materials costs; and the frequency that the preventative measure's service is performed or the constants of the probability distribution that determine the probability of that corrective measure occurring in a year.

A pilot implementation of the method was prepared by SunSpec Alliance and NREL as a spreadsheet, reviewed by Working Group members, and is available as supplementary material to this paper. (Please see the PDF; click on the paper clip icon to open the attachments and download the supplemental Excel spreadsheet.) The online deployment of the PV O\&M cost model version 1 is available at https://apsuite.sunspec.org. In the software implementation, the user may edit each service or add new services. The user can manually delete services that are not applicable or can use program logic and a higher level of inputs describing a system to determine which services are applicable to a system. Each service has the following parameters:

- Description is text describing the service;

- Service type is the type of O\&M activity: cleaning, emergency response, inspection, management, preventive maintenance, testing, and repair/corrective maintenance;

- Component type refers to AC wiring, asset management, cleaning/vegetation removal, DC wiring, documents, electrical, inverter, mechanical, meter, monitoring, PV array, PV module, roof, tracker, or transformer;

- User-defined category allows the user to sort services according to categories defined by the user;

- Applicability is logic ("if" statements) that determines whether the service is included in a cost model or not. For example, services related to a tracking mechanism would not be applicable to a fixed-tilt system. Inputs that may trigger the applicability of a measure include:

○ Mounting Location: Rooftop or ground mount

○ Tracking: Fixed tilt, one-axis tracking, or two-axis tracking

○ Rooftop Rack Type: Ballasted, attached, or both ballasted and attached

- PV Sector: All, residential, commercial, or utility. For example, periodic inspections are not applicable to the residential sector, and services related to regulatory compliance are applicable only to the utility sector.

○ Environmental Conditions: Snow, humidity, heat, pollen, high wind, hail, and salt air (marine location); Diesel soot; industrial emissions; and bird populations are inputs that may affect applicability of measures depending on the logic programmed for each measure. For example, pollen or bird populations would make additional cleaning applicable with the logic programmed as default with those measures.

- Inverter Types: String inverter, central inverter, micro-inverter, or DC optimizers. Replacement of the entire inverter applies to string and micro-inverters, whereas 
for central inverters, components are replaced instead (data acquisition, control, drivers, transistor matrix, inductive components, and capacitors).

○ Covered by Warranty: Materials; covered by warranty: Labor; warranty or service package type: If a service occurs within a warranty period, or is covered within a service package, the cost of the hardware, the labor, or both is reduced by the warranty coverage. Notice, then, that this cost model does not cover the total cost of O\&M, just the cost to the system owner after warranty coverage has reduced the total cost. This logic is implemented with "if" statements that compare a given year to the year that a warranty expires.

- Applicable Unit: The unit multiplied by per-unit costs to estimate the cost of a service. For example, the applicable unit for fuse replacement would be number of fuses, while the applicable unit for cleaning would be square meters of PV array surface. The applicable unit for grounds maintenance would be acres of ground area.

- Labor Hours per Unit: Number of hours of labor required to perform the service.

- Service Provider: Administrator, cleaner, designer, inspector, inverter specialist, journeyman electrician, master electrician, mechanic, network/IT, pest control, PV module/array specialist, roofing, structural engineer, mower/trimmer, or utilities locator. Each service provider has an hourly rate in the cost model. The user may add or edit service providers and hourly rates.

- Material/Other Cost per Unit: Costs of replacement parts and other materials such as water, detergent, or paint required to complete the service.

- Comments and Reference: Any comment notes to, or by, the user plus, a reference for where information about the service came from.

The model allows customization of all variables to suit system configuration, job time estimates, failure rates, and local costs.

Administrative and preventive maintenance measures are on defined schedule intervals (for example, once per year), whereas corrective-maintenance measures are scheduled according to a failure distribution curve (default of Weibull distribution) for each measure.

The flowchart of Figure 2 is used for the calculation of annual cash flow. Program logic compares the year under consideration with the warranty period to determine whether the warranty is in effect. Indicators of whether the warranty covers materials, labor, or both, are used to adjust the cost of services that occur in the warranty period. Initial cost of labor and materials is escalated to the year under consideration according to the specified inflation rate. The number of hours specified for a service is multiplied by the labor rate of the service provider to estimate labor cost. The estimated cost of a service is multiplied by the calculated probability of that service occurring in the year under consideration, and for the net present value the annual costs are discounted according to the discount rate, $\mathrm{d}$, as illustrated in Figure 3 . The logic is repeated for each service in the cost model and is repeated for each year in the analysis period to estimate annual cash flow from year to year. These annual costs are useful for budgeting for PV O\&M services, and when discounted to their present value can inform life cycle cost decisions, which 
is the topic of Section 4. Also, annual cost calculated in this way does not estimate the maximum exposure to unplanned cost, which is the topic of the reserve account discussion of Section 6.

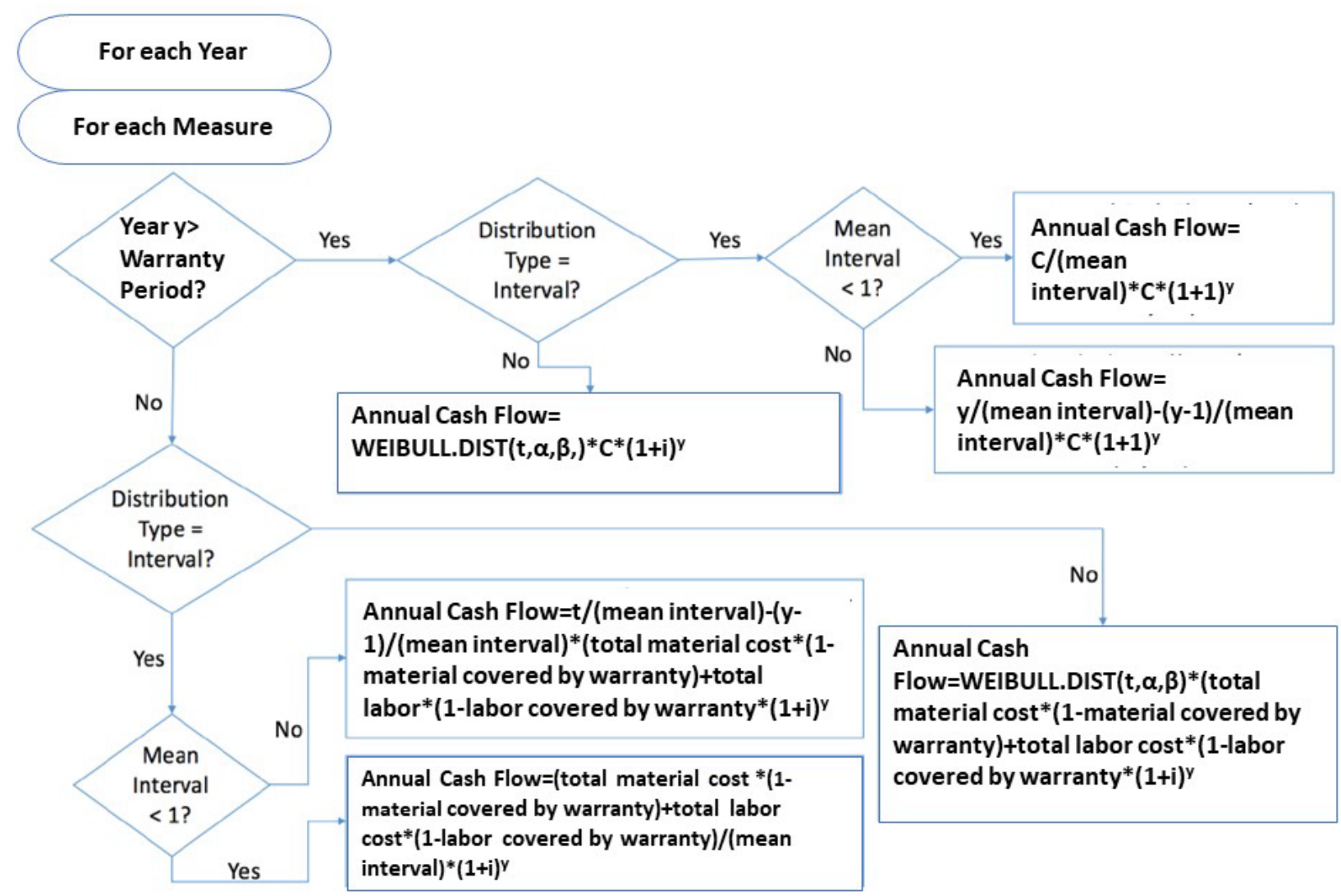

Figure 2. Flowchart for calculation of annual cost (\$/year) for each service and year of analysis period

Source: Deot et. al. 2017 
Consider a replacement that would cost

$\$ 10,000$ if it occurred in year 1 :

$\mathrm{C}_{\text {replacement }}=\$ 10,000$

a) Annual Inflation
$*(1+i)^{\wedge} t$
b) Failure Distribution
$*$ Weibull_dist(year, alpha, beta)
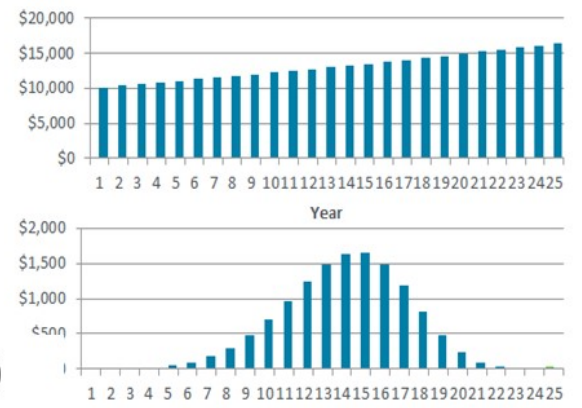

Year

c) Within Warranty Period?

Within Analysis Period?

d) Net Present Value

$$
\text { =NPV(discount rate, } 1,2 \text {...) }
$$
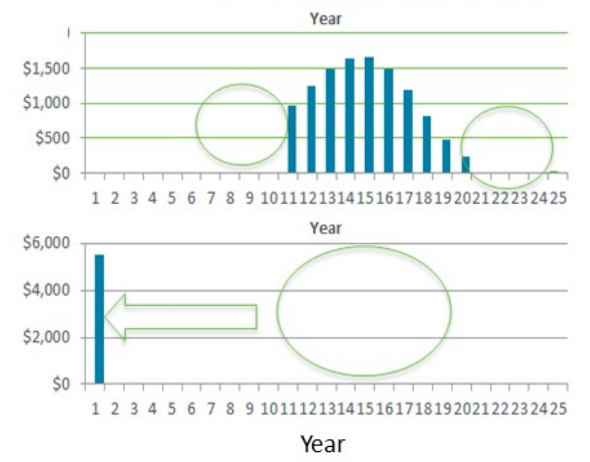

Figure 3. Illustration of how annual cash flows are calculated considering an example of replacement costing $\$ 10,000$. a) $\$ 10,000$ O\&M cost would be escalated according to inflation; b) the replacement cost is multiplied by the failure probability to provide the cash flows modified by failure probability distribution; c) each year's cash flow is modified by logic related to warranty and analysis periods; and d) each year of future cost is discounted to present value and summed for net present value.

Source: Andy Walker, NREL 


\section{$5 \quad$ Net Present Value and Related Cost Indicators}

This calculation of annual cost based on failure distribution serves as a basis for estimating net present value of O\&M expenditures. Net present value is useful in a life cycle cost analysis (for a feasibility study) or to estimate cost indicators and metrics, such as cents/kilowatt hours (kWh) delivered or levelized $\$ / \mathrm{kW} /$ year.

\section{Net Present Value O\&M Costs (Project Life):}

The net present value of the O\&M costs represents the annual costs each year inflated to the year that they occur according to an inflation rate, $\mathrm{i}$, then discounted to their present value according to the discount rate, $\mathrm{d}$, and summed over the years of the analysis period. Net present value O\&M cost (\$) is useful for informing life cycle cost decisions, such as choosing among alternatives. For example, an inverter might have a lower initial cost but a larger annual O\&M cost than an alternative, and a life cycle cost analysis would be required to compare the two.

\section{Annualized Life Cycle Cost of O\&M Costs (\$/Year):}

The annualized life cycle cost of O\&M costs (\$/year) is calculated as the net present value divided by a present-worth factor calculated from the inflation and discount rate. So even though the cost varies considerably from year to year based on scheduled measures and failure distributions, this provides the annual value levelized over all the years of the analysis period. This requires some explanation because of the two estimates that put cost on an annual basis. The annual O\&M cost (\$/year) is the schedule of costs in each year of an analysis period, including variations from year-to-year caused by warranties and failure probabilities. These costs are discounted according to the discount rate and summed to calculate net present value. Now that net present value is divided by a present-worth factor (calculated from inflation rate, discount rate, and analysis period) to get annualized life cycle cost of O\&M cost. Annualized life cycle cost of O\&M cost is a smoothed-out, levelized version of annual O\&M cost, and is presented in Equation 2.

Equation 2

$$
\text { Annualized O\&M Costs }=\frac{\text { Net Present Value O\&M Costs }}{\left[\left(\frac{(1+i)}{(d-i)}\right)\left(1-\left(\frac{(1+i)}{(1+d)}\right)^{T}\right)\right]}
$$

Where:

- $\quad \mathrm{i}=$ Inflation Rate per year

- $\mathrm{d}=$ Discount Rate per year

- $\mathrm{T}=$ duration of the analysis period (years)

\section{Annualized Unit O\&M Costs (\$/kW/Year):}

The annualized unit O\&M costs $(\$ / \mathrm{kW} /$ year) represents the annualized O\&M costs divided by the plant size $(\mathrm{kW})$ and the rated DC nameplate capacity of the plant, as in Equation 3. 
Equation 3

$$
\text { Annualized Unit O\&M Costs }=\frac{\text { Annualized } O \& M \text { Costs }}{\text { Plant Size }(k W p D C)}
$$

Net Present Value (Project Life) per Watt:

The net present value per watt of rated capacity (DC) is the net present value divided by the rated plant size (W DC), as in Equation 4.

Equation 4

$$
\text { Net Present Value (Project Life) per Watt }=\frac{\text { Net Present Value O\&M Cost }}{\text { Plant Size }(k W p D C)}
$$

\section{Levelized O\&M Cost per kWh Delivered (\$/kWh):}

The levelized O\&M cost per $\mathrm{kWh}$ delivered $(\$ / \mathrm{kWh})$ represents the net present value O\&M costs divided by the net present value of the energy delivery, which is the energy delivery for each year reduced by a specified degradation rate (default value $=0.5 \%$ per year), then discounted to present value according to the discount rate and summed over all years of the analysis period, as in Equation 5.

Equation 5

Net Present Value (Project Life) per kWh

$$
=\frac{\text { Net Present Value O\&M Cost }}{\sum_{y=1}^{\text {life }}\left[\text { Annual Production }\left(\frac{k W h}{y e a r}\right) \frac{(1-g)^{y}}{(1+d)^{y}}\right]}
$$




\section{Reserve Account}

Annual O\&M cost is useful for budget planning, and net present value is useful to inform life cycle cost decisions; however, financiers and system operators also need to know the maximum exposure, which is the amount that should be secured in a line of credit or reserve fund to cover the worst-case scenario of O\&M costs. The amount of money that might be needed in a given year is the value of the reserve account. Reserve account amounts are not added together year to year, because such a sum of maximum exposure amounts would be meaningless.

The need to plan a reserve account is exemplified by a 924-kW carport system in San Diego that was down for 2 years because the funds to replace a failed inverter had to be obtained through a long budget request process. A reserve account, which could be in the form of a line of credit, would have been available to replace the inverter immediately and avoid the 2 years of lost production.

Calculation of the reserve account is derived using Newton's Binomial Theorem and expands a binomial failure probability associated with each component type to calculate the probability that different numbers of a component type will fail. Each term of the binomial expansion represents the probability that a certain number of a component type will fail. Thus, calculation of the required reserve account in the year under consideration depends not only on the probability and cost of replacements but also on the desired probability that the calculated reserve account will be sufficient.

Begin with a very simple example of this method to set the stage for the general derivation. Consider a PV system with two string inverters $(\mathrm{N}=2)$, each with a replacement cost of $\$ 10,000$ were it replaced in Year 20, and each inverter's behavior is described by a Weibull failure distribution with a mean failure interval of $\beta=20$ years and a shape factor of $\alpha=5.0$. In Year 20, this failure distribution would predict a probability of failure of $\mathrm{Q}=0.092(9.2 \%)$. $\mathrm{P}$ is the probability that a component will not fail $\mathrm{P}=(1-\mathrm{Q})$, and, thus, the probability of nonfailure is $\mathrm{P}=$ $0.908(90.8 \%)$. The probability that we will have to replace neither of the two inverters is then $\mathrm{P}_{1} \mathrm{P}_{2}=\mathrm{P}^{\wedge} \mathrm{N}=(0.908)^{\wedge} 2=0.824$. So, we get an $82.4 \%$ chance that the reserve account would be sufficient even with no funds in the reserve account (none will be needed in Year 20).

The probability that we will have to replace either of the two inverters is $\mathrm{P}_{1} \mathrm{P}_{2}+\mathrm{P}_{1} \mathrm{Q}_{2}+\mathrm{P}_{2} \mathrm{Q}_{1}=$ $0.824+(0.908 * 0.092)+(0.092 * 0.908)=0.991$. So, there is a $99.1 \%$ chance that $\$ 10,000$ in the reserve account would be sufficient for Year 20. If we have enough in reserve to replace both inverters (the reserve account $=\$ 20,000$ ), then the probability that the reserve account is sufficient is $\mathrm{P}_{1} \mathrm{P}_{2}+\mathrm{P}_{1} \mathrm{Q}_{2}+\mathrm{P}_{2} \mathrm{Q}_{1}+\mathrm{Q}_{1} \mathrm{Q}_{2}=0.991+(0.092 * .092)=1.00$.

Certainty that the reserve account will be sufficient is a business decision involving the fees and costs of a line of credit; lost revenue of extended downtime should reserves be insufficient to make timely repairs; and contractual obligations regarding availability and performance. One working group member, representing a bank, thought that $40 \%$ of capital expenditures would be an appropriate reserve account amount. The method presented here suggests that the amount could be much smaller, especially if the certainty that the reserve account is sufficient is relaxed. 
We generalize this approach to a very large number of components, $N$, where $n / N$ is the fraction of the total number of components funded in the reserve account; $\mathrm{R}$ is the desired probability that the reserve account will be sufficient; and Q is the probability of failure in each year of the analysis period according to the failure distribution. This is done for each measure (PV module replacement, inverter replacement, and so on) and added up to calculate the total amount in the reserve account for each year of the analysis period.

$\mathrm{P}$ and $\mathrm{Q}$ are defined such that $(\mathrm{P}+\mathrm{Q})=1$. The polynomial $(\mathrm{P}+\mathrm{Q})^{\wedge} \mathrm{N}$ is thus also equal to unity.

$(\mathrm{P}+\mathrm{Q})^{\mathrm{N}}=1$

$(\mathrm{P}+\mathrm{Q})^{\mathrm{N}}=\mathrm{P}^{\mathrm{N}}+\mathrm{NP} \mathrm{N}^{\mathrm{N}-1} \mathrm{Q}+\mathrm{N}(\mathrm{N}-1) \mathrm{P}^{\mathrm{N}-2} \mathrm{Q}^{2} / 2 !+\ldots+\mathrm{Q}^{\mathrm{N}}=1$

Or in Equation 6 as summation notation:

Equation 6

$$
(P+Q)^{N}=\sum_{k=0}^{N} \frac{N !}{(n+i) ! i !} P^{(N-k)} Q^{k}
$$

The powers of $\mathrm{P}$ in Equation 6 start at $\mathrm{N}$ and decrease by 1 in each term until they reach 0 . The first term in the binomial expansion is $\mathrm{P}^{\wedge} \mathrm{N}$, the probability that none of the components of that type will fail in the year under consideration. The second term is the probability that one will fail, and the others will not fail. The powers of Q start at 0 and increase by 1 until they reach $\mathrm{N}$. The final term $\mathrm{Q}^{\wedge} \mathrm{N}$ is the probability that all of the components of that type will fail. In summation notation, $\mathrm{k}$ is an index referring to the sequence of terms, and since there are $\mathrm{N}+1$ terms in the expansion, $\mathrm{k}$ starts at zero, rather than 1.

This polynomial is expanded, and each term examined, to evaluate the probability that each number of components might fail in a year, and thus must be covered with funds for the replacement in the reserve account. The polynomial expansion can be accomplished with any number of terms (any number of components, $\mathrm{N}$ ). The above must be calculated for each type of component. The above also must be evaluated for each year of the analysis period, because the probability of failure Q changes with each year according to the Weibull failure distribution for each type of component. The number of replacement components to be funded in the reserve account thus calculated is multiplied by the cost of replacing each component escalated to the year, according to the inflation rate.

Toward the end of a project's contractual life, it might no longer make sense to carry a reserve account or replace larger pieces of equipment. For example, it seems unlikely that an owner would replace a central inverter in Year 19 of a 20-year contract. The return on that investment may be negative. Here, the reserve account amount is based only on probability of failure and is high in the final years. Thus, the methodology described here does not account for that decision to not fund repairs or replacements in the final years of the analysis period.

To explore the dependence of the reserve account amount on different failure probabilities, Q, and different probabilities that the reserve account will be sufficient, $R$, the equations for reserve 
account for 10 components ( $\mathrm{N}=10$ and 11 terms in expansion) are presented in Section 5.1, and the results are plotted in Figure 4. Adding more to $\mathrm{N}$ would add more points to these curves but not change the position of the curves, so the trends can be viewed generally if we interpret $1 / \mathrm{N}$ as $10 \%$ of the total number of components, $2 / 10$ as $20 \%$, and so on, up to $10 / 10$ as $100 \%$ of the components. Note that the last calculated probability is equal to unity. It is understood that if we have enough funds in the reserve account to cover $\mathrm{n} / \mathrm{N}=10 / 10$, or $100 \%$ of the component replacements, we can be certain (probability $=1.0$ ) that the reserve account will be sufficient. The fraction $\mathrm{n} / \mathrm{N}$ so determined is then multiplied by the actual number of components $\mathrm{N}$ to determine the number of components for which the reserve account must have funding to cover replacements.

\subsection{Example of Reserve Account Calculation (10 Components)}

In this example, we consider 10 components, each with a replacement cost of $\$ 1,000$ in a given year. The result of the Weibull failure probability is $\mathrm{Q}=0.05$ probability of failure in this given year. The desired probability that the reserve account will be sufficient is $\mathrm{R}=0.999(99.9 \%$ certainty). These values are listed in Table 2. The $\mathrm{Q}$ value is used in generation of an interpolation table, and then the $R$ value is used to interpolate the value of $n / N=0.303$. The resulting dollar amount to keep in the reserve account to cover failure of this component in the given year is $(0.303) *(10) *(\$ 1,000)$, or $\$ 3,030$, as shown in Table 2 .

Table 2. Inputs and Outputs of Reserve Account Calculation

INPUTS

\begin{tabular}{|l|l|}
\hline$N=$ Number of a type of Component & 10 \\
\hline C replacement $=$ Replacement of cost of each component & $\$ 1,000$ \\
\hline $\begin{array}{l}\text { Q }=\text { Probability that type of component will fail in a } \\
\text { given year (varies by Weibull distribution) }\end{array}$ & 0.05 \\
\hline $\begin{array}{l}\mathrm{R}=\text { Desired probability that reserve account will be } \\
\text { sufficient }\end{array}$ & 0.999 \\
\hline
\end{tabular}

OUTPUTS

\begin{tabular}{|c|c|}
\hline $\begin{array}{l}\text { Required } \mathrm{n} / \mathrm{N}=\text { required fraction of total number of a } \\
\text { specific type of component covered by reserve } \\
\text { account in order to achieve desired probability that } \\
\text { reserve account will be sufficient in a given year }\end{array}$ & 0.303 \\
\hline $\begin{array}{l}C \text { reserve account }=\text { amount in reserve account for } \\
\text { this type of component in a given year }\end{array}$ & $\$ 3,030$ \\
\hline
\end{tabular}

For practical problems, only Q-values less than 0.1 , and R-values greater than 0.9 are of interest, but higher Q-values and the complete range of R-values are shown to illustrate how the function behaves over the entire domain. Referring to the chart of Figure 4, if a component has a 4\% probability of failure in a year $(\mathrm{Q}=0.04$, marked by round dots in Figure 4$)$, and there is enough in the reserve account or inventory of spare parts to replace $10 \%$ of the total number of that component in the system $(\mathrm{n} / \mathrm{N}=0.1)$, then there is a $94 \%$ chance that amount would be sufficient in reserve to cover failures. 


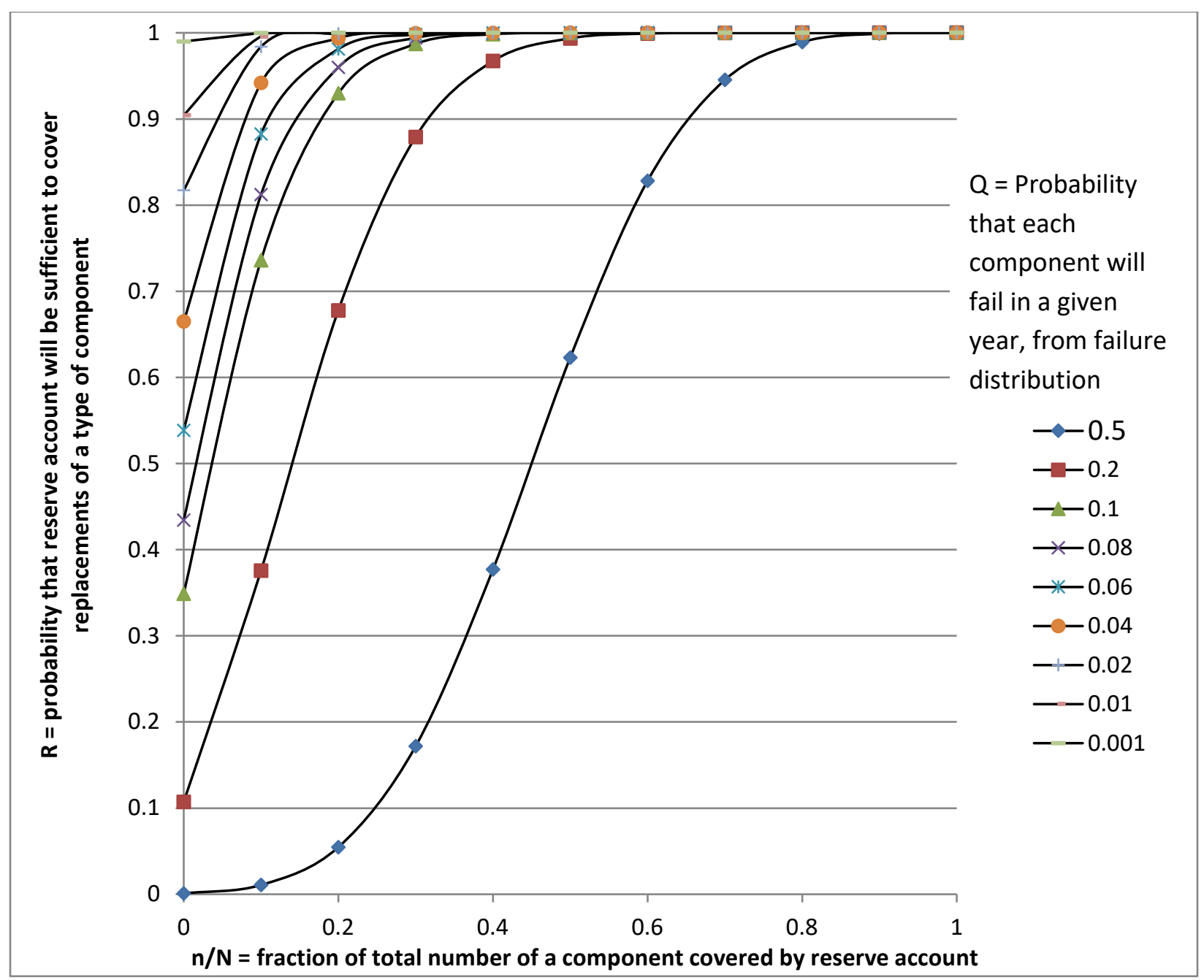

Figure 4. Chart of probability that reserve account will be sufficient as a function of fraction of total number of component in reserve, and for different values of failure probability

Source: Andy Walker, NREL

Figure 5 is used for the calculation of the reserve account. The value obtained from the flowchart is compared with the annual cash flow for that service and for the same year of analysis, and the maximum amount is chosen as the annual reserve account. The logic is repeated for each service in the cost model and is repeated for each year in the analysis period to calculate reserve account. 


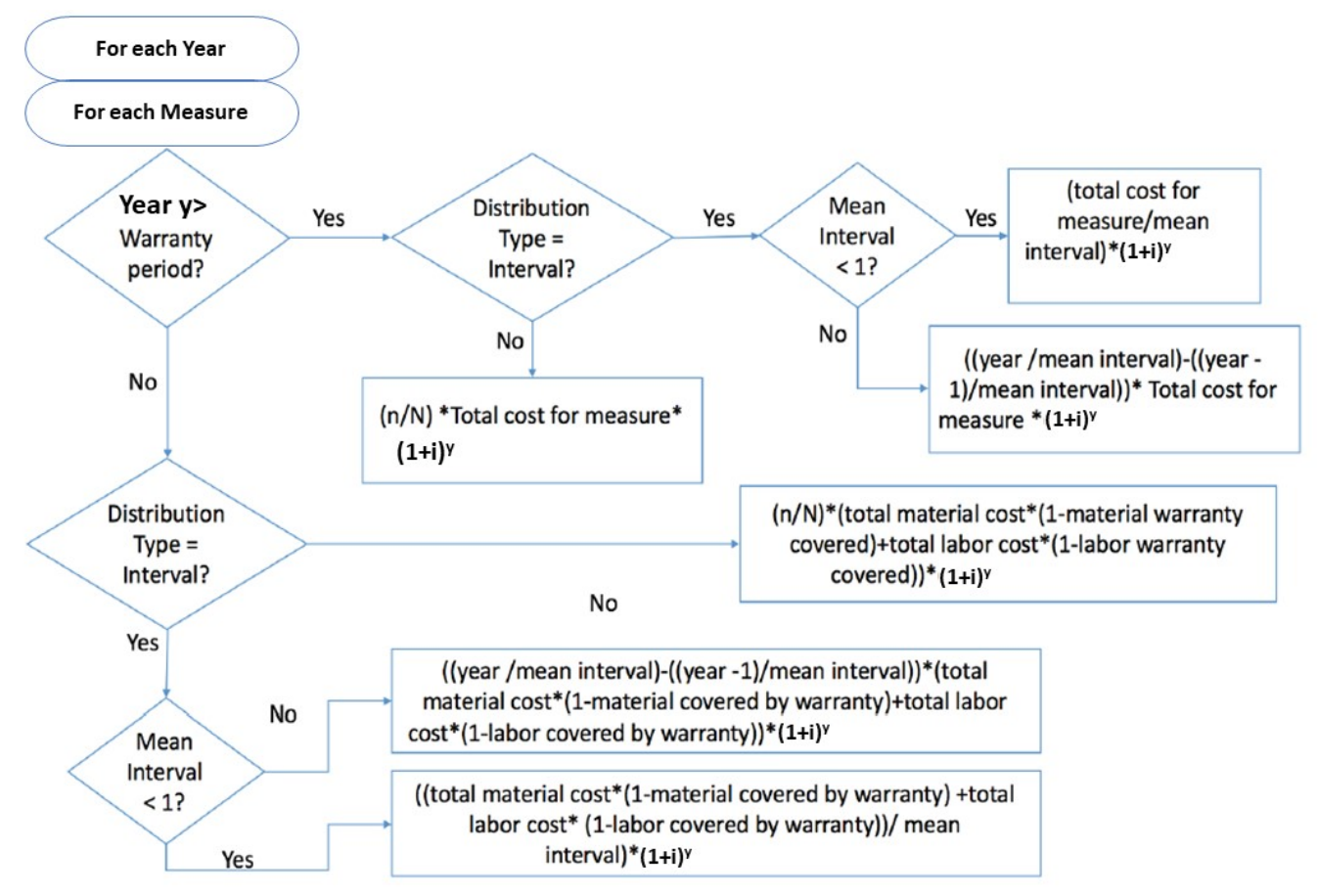

Figure 5. Flowchart for calculation of reserve account associated with each service and each year of the analysis period

Source: Deot et al. 2017 


\section{Implementations of This PV O\&M Cost Model}

\subsection{Pilot Implementation in Spreadsheet Program}

The SunSpec Alliance and NREL staff prepared a spreadsheet implementation of the method so PV O\&M Working Group members could review the approach and calculations and recommend default numbers for the frequency and cost of O\&M services. The resulting spreadsheet model is included with the publication of this paper as supplementary material.

Figure 6 lists key inputs on an input tab of a spreadsheet program to pilot the method for a 10MW ground-mounted PV system. The list of inputs includes general inputs, such as economic parameters; system inputs, describing size and type of components in the system; and environmental parameters, such as snow or bird populations, which would trigger the applicability of measures associated with snow removal for site access and cleaning of bird droppings. The details associated with each measure, such as labor category, hours of labor to perform the measure, and cost of materials and supplies (not shown in Figure 6), should also be considered as equally important inputs that the user is expected to review and modify. 


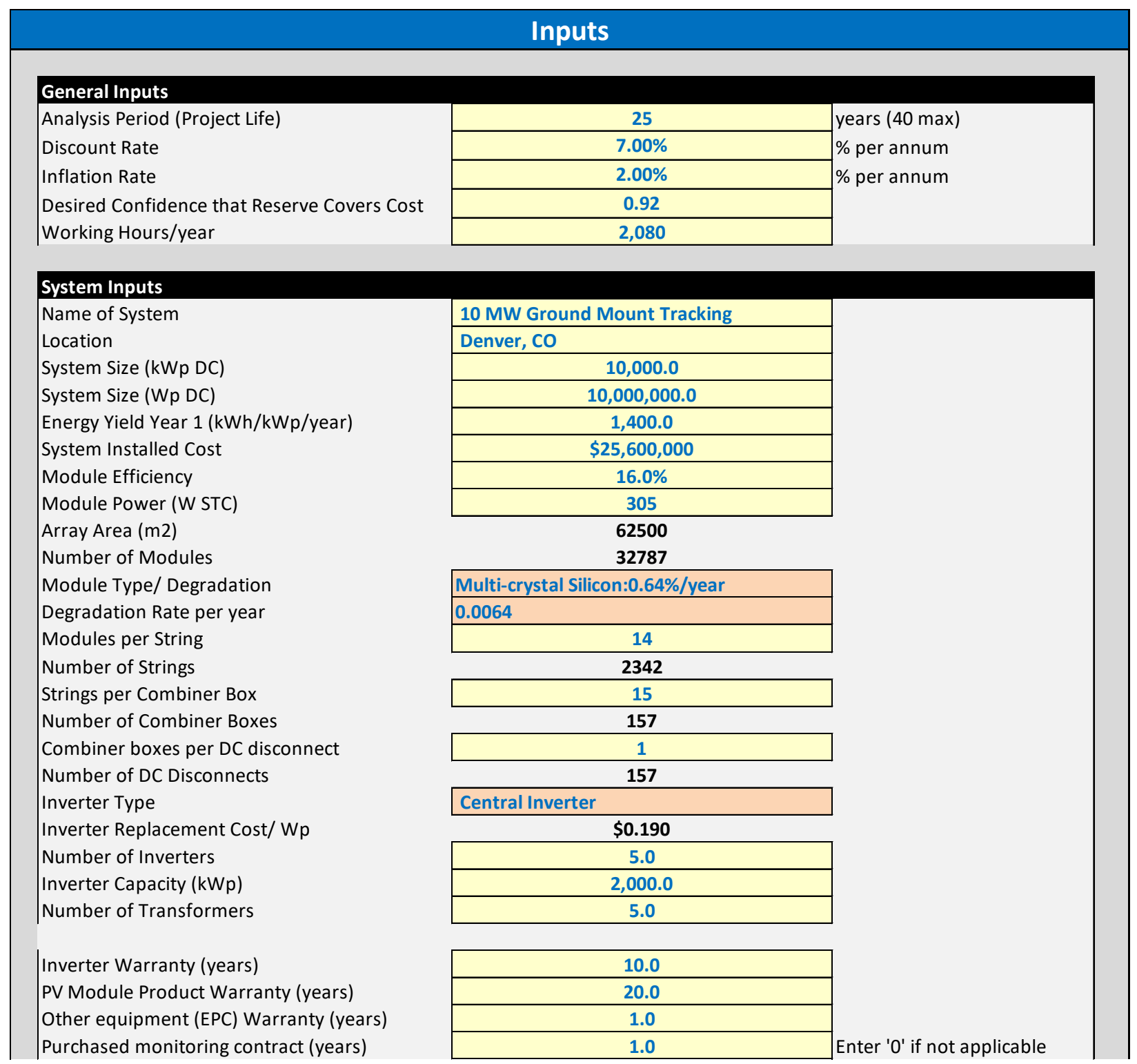

Figure 6. Partial list of inputs for spreadsheet deployment of PV O\&M cost model, with an example of a 10-MW ground-mounted PV system

Source: Andy Walker, NREL

Figure 7 shows results from the prototype spreadsheet calculation. Results include annual cost for each year of the analysis period, life cycle cost, and key cost indicators, such as O\&M costs per $\mathrm{kW}$ of installed capacity or per kWh of energy delivered. Results also include the amount of money that should be kept in a reserve account or line of credit, or spare parts inventory, to provide the desired level of certainty that the reserve account will be sufficient to cover unplanned costs for each year of the analysis period.

For the example considered (a 10-MW ground-mounted system with 10 inverters), annual costs vary from less than $\$ 100,000 /$ year early in the analysis period to almost $\$ 400,000$ late in the analysis period, with an annualized value of $\$ 143,581 /$ year or $\$ 14.36 / \mathrm{kW} /$ year. The net present value is $\$ 2,044,656$, or $\$ 0.013 / \mathrm{kWh}$ per unit of delivered energy. Assuming a desired probability 
of $92 \%$, the amount to keep in reserve varies from less than $\$ 100,000$ early in the analysis period to a maximum of $\$ 800,840$ in Year 21 . The detailed services can be sorted by service type (type of labor), by component type, as shown in Figure 7, or in different ways as desired by the user.

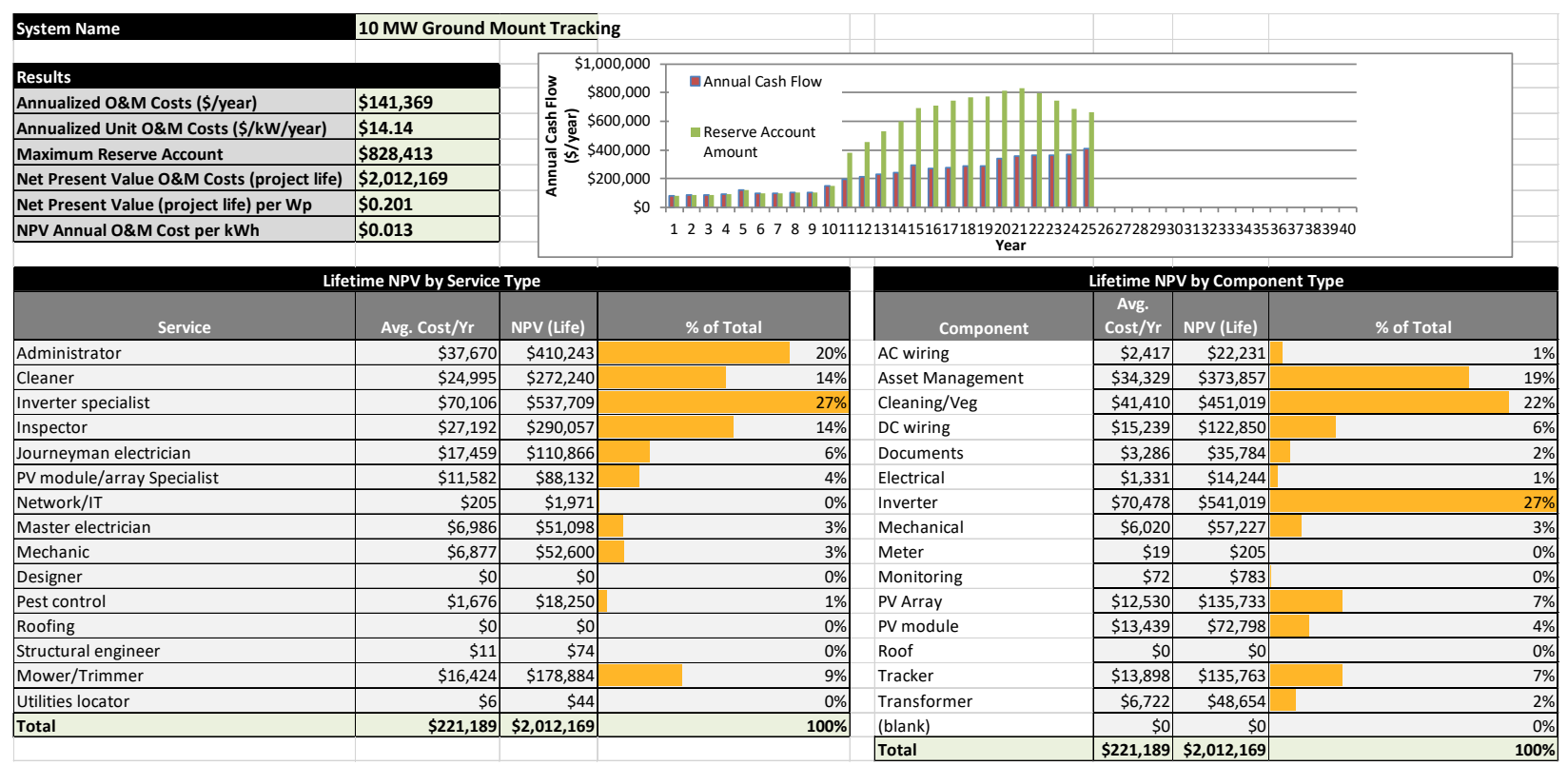

Figure 7. Example report from PV O\&M cost model for 1-MW ground-mounted system

Source: Andy Walker, NREL

\subsection{Online Version of PV O\&M Cost Model}

Software designers and programmers at SunSpec Alliance produced an online version of the PV O\&M cost model available at apsuite.sunspec.org. (one will need to register themselves to get access to the online PV cost model).AP Suite stands for Asset Performance Suite and includes both the PV O\&M Cost Model and oSPARC, which logs system performance. This suite enables the cost model of a PV system to be linked to the archived performance of that same system.

Figure 8 lists some inputs for the online version of the PV O\&M cost model. The list of inputs is the same as the precursor spreadsheet version, but inputs can be grouped by owner, portfolio, and PV system, and the program allows for the storage of multiple cost models for an individual PV system so scenarios can be compared. 


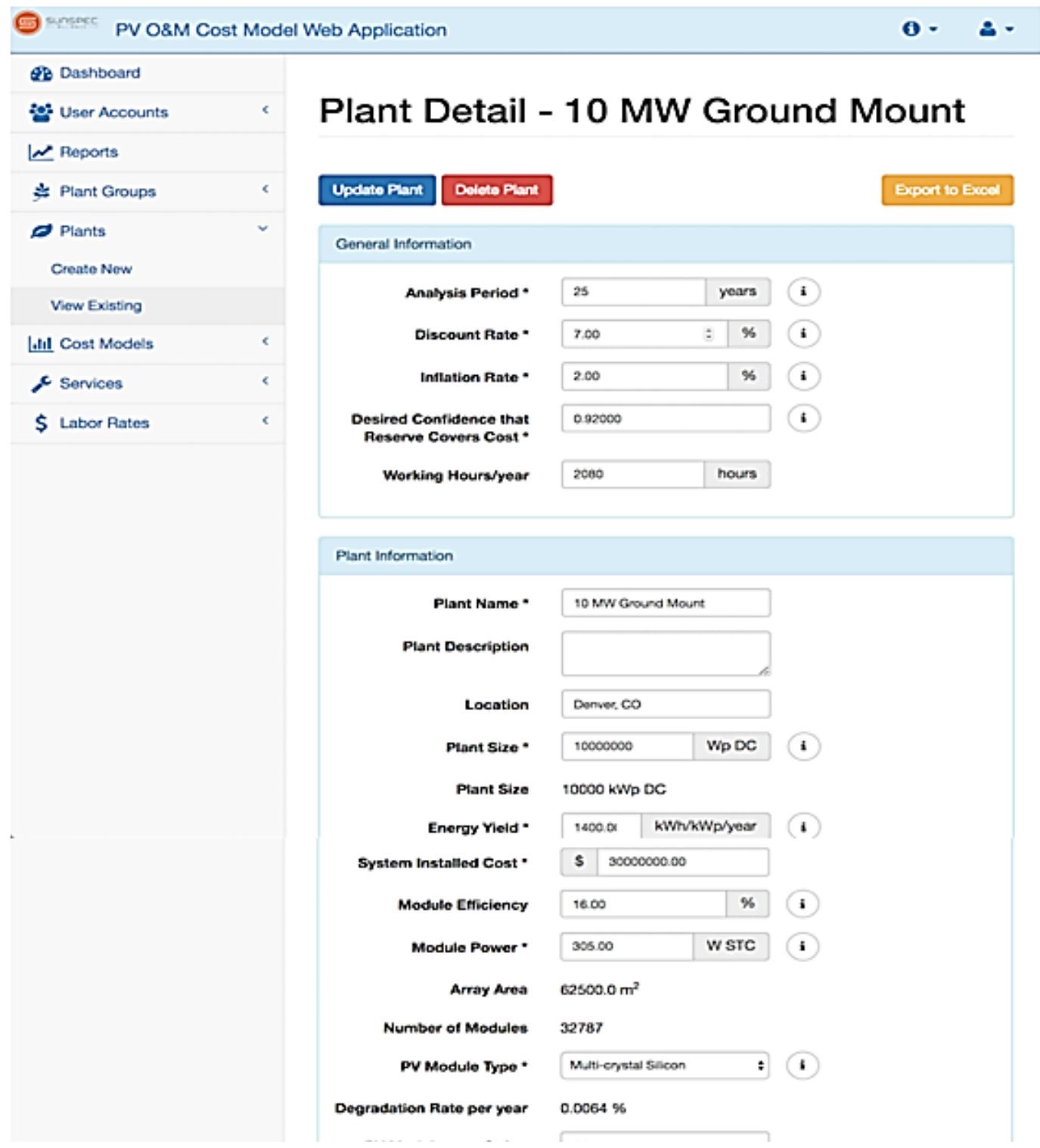

Figure 8. Beginning of data input sheets for online version of PV O\&M cost model, available at apsuite.sunspec.org.

Reports generated by the online version of the PV O\&M cost model are, as with the spreadsheet version described previously, annual O\&M cost, net present value of PV O\&M costs, and reserve account amount for each year. As with the spreadsheet version, key indicators, such as $\$ / \mathrm{kW} /$ year and $\$ / \mathrm{kWh}$ delivered, are also presented. The detailed results can be sorted by category (Administrative, Operations, Preventive, and Corrective), by service type (electrician, cleaner, and so on), and by component type (PV modules, inverters, and so on). Figure 9 shows a screen capture of the Report screen showing results for the 10-MW ground-mounted system that we are considering for an example. 


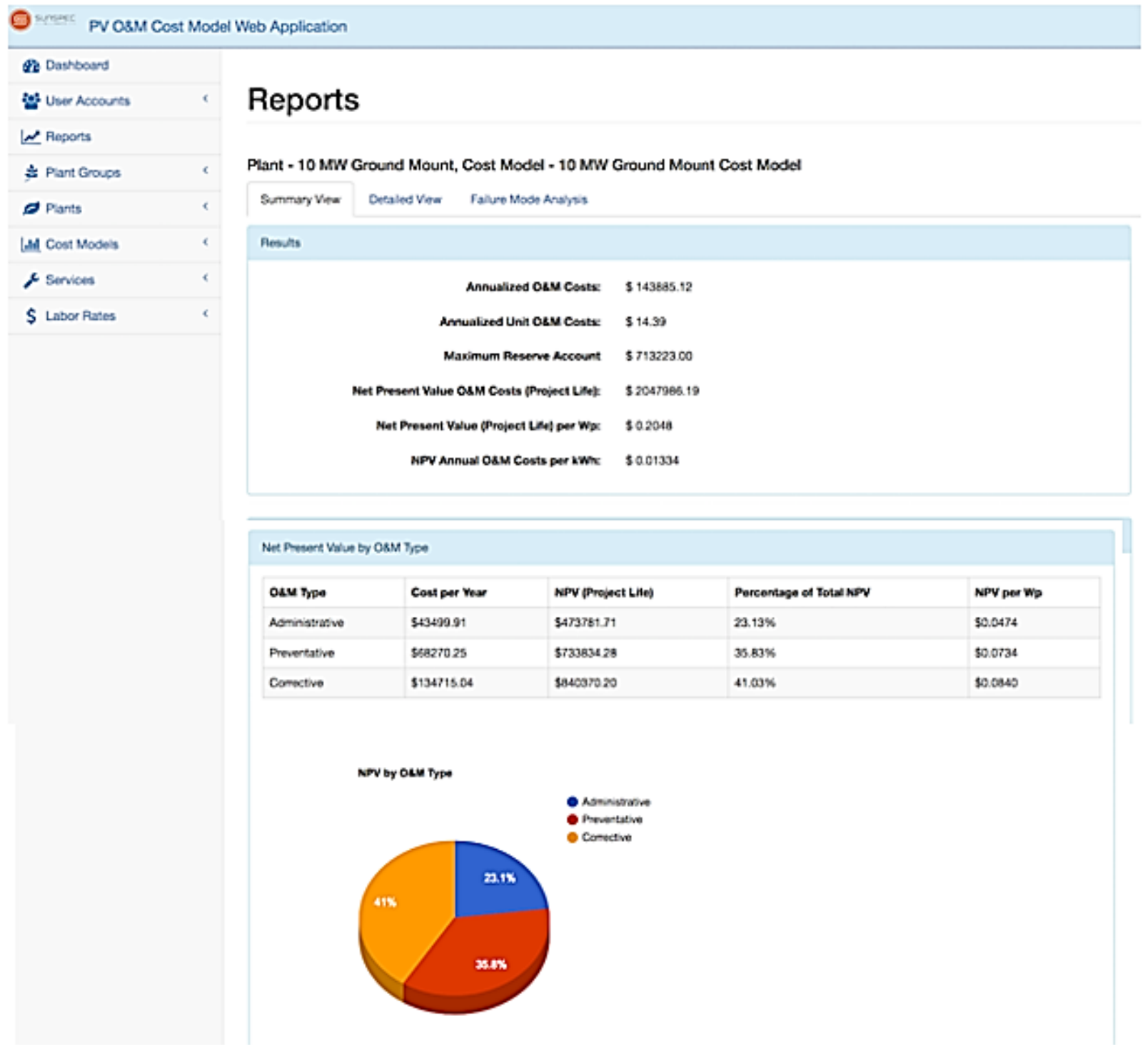

Figure 9. Sample report from online version of PV O\&M cost model, showing annual O\&M costs, net present value, and reserve account amount for each year of the analysis period, and key indicators such as $\$ / \mathrm{kW} /$ year and $\$ / \mathrm{kWh}$ delivered.

Source: apsuite.sunspec.org 


\section{Conclusion}

In this report, we present a method to calculate annual O\&M costs, net present value of life cycle costs, and reserve account amount for O\&M of PV systems. Annual O\&M cost is useful for planning O\&M budgets, net present value is useful in evaluating the financial prospectus of potential project options and alternatives, and reserve account amount is useful for planning required reserves that should be set up through financial mechanisms, such as line of credit, so that repairs may be funded and accomplished quickly. In addition, the method and resulting software calculate key indicators that use economic calculations to levelize these costs into a standard per-kW, per-year basis $(\$ / \mathrm{kW} /$ year) or a per-kWh delivered basis $(\$ / \mathrm{kWh})$. Results are sorted to provide totals by category, type, and configuration of system equipment, and type of service provider. This detail is useful for identifying areas of high cost that should be the focus of efforts to reduce cost. The approach is general and can accommodate systems of different size, application (residential, commercial, utility), and under different environmental conditions.

We have concentrated on developing the methods, calculations, and analytic framework, and the method has been programmed into an online implementation available at apsuite.sunspec.org. The online implementation of the PV O\&M cost model software is populated mainly with default values for labor and materials costs. While these default values reflect the considerable experience of the members of the PV O\&M Working Group that provided and reviewed them, the intention is that default values would be replaced by actual cost experience of program users.

Recommendations for future work include an encouragement for system and fleet operators to share their actuarial data on operations and maintenance in order to advance the accuracy and utility of cost estimating tools. Feedback from actual costs should be carefully curated to refine future PV O\&M cost estimates. A covariance analysis is recommended rather than single variable regression in order to represent inter-dependencies between the O\&M cost model lineitems (eg serial defects, cascading failures) 


\section{References}

Barbose, Galen L., Naïm R. Darghouth, Dev Millstein, Kristina Hamachi LaCommare, Nicholas DiSanti, Rebecca Widiss. Tracking the Sun 10: The Installed Price of Residential and NonResidential Photovoltaic Systems in the United States. Berkeley, CA: LBNL. September 2019. https://emp.lbl.gov/publications/tracking-sun-10-installedprice/?utm source $=$ newsletter $84 \&$ utm medium $=$ email\&utm campaign $=$ Constant $\% 20$ Contact.

Bolinger, Mark, Joachim Seel, and Kristina Hamachi LaCommare. "Utility-Scale Solar: An Empirical Analysis of Project Cost, Performance, and Pricing Trends in the United States." LBNL-2001055. Berkeley, CA: LBNL. September 2017. https://emp.lbl.gov/publications/utility-scale-solar-2016-empirical

Brehaut, Cedric. “Global Solar PV O\&M 2017-2022.” GTM. December 2017. http://splunk01.nrel.gov/store/GTM/GTM2017/GTM_GSPVOM_2017-2022.pdf.

Brehaut, Cedric. "Megawatt-Scale PV O\&M and Asset Management 2016-2021." GTM. November 2016. http://splunk01.nrel.gov/store/GTM/GTM2016/GTM_MSPVOMAM_2016.pdf.

Castillo-Ramírez, Alejandro, Diego Mejía-Giraldo, and Nicolás Muñoz-Galeano. "Large-Scale Solar PV LCOE Comprehensive Breakdown Methodology.” August 10, 2017. https://www.ecopetrol.com.co/especiales/ctyf-december-2017/V7_N1_08.html.

Deot, J., B. Fox, T. Tansy, A. Walker, and A. Pochiraju. PV O\&M Cost Model User Guide. Prepared by SunSpec Alliance. February 2017. https://sunspec.org/wpcontent/uploads/2016/03/SunSpecPVOMCostModelUserManual-Beta.pdf.

EPRI (Electric Power Research Institute). Budgeting for Solar PV Plant Operations \& Maintenance: Practices and Pricing. Palo Alto, CA: EPRI, Sandia National Laboratories. December 2015. http://prod.sandia.gov/techlib/access-control.cgi/2016/160649r.pdf.

Green, A. E., and A. J. Bourne. Reliability Technology. New York: John Wiley and Sons, 1972.

IRENA (International Renewable Energy Agency). "Renewable Power Generation Costs in 2017 - 3. Solar Photovoltaics.” 2018. https://www.irena.org//media/Files/IRENA/Agency/Publication/2018/Jan/IRENA_2017_Power_Costs_2018.pdf.

Klise, G., J. Freeman, O. Lavrova, and R. Gooding. PV-RPM v2.0 beta - SAM Implementation DRAFT User Instructions. SAND2017-7294R, Sandia National Laboratories, Albuquerque, NM. July 7, 2017. https://sam.nrel.gov/pvrpm.

Klise, Geoffrey, Olga Lavrova, and Renee Gooding. PV System Component Failure and Repair Data Compilation and Analysis. SAND2018-1743. February 2018. https://prodng.sandia.gov/techlib-noauth/access-control.cgi/2018/181743.pdf.

Mood, A.M., F. A. Graybill, and D. C. Boes. Introduction to the Theory of Statistics. New York: McGraw-Hill, Inc., 1974. 
NREL. 2018a "Comparative PV LCOE Calculator." Photovoltaic Research. Accessed April 9, 2018. https://www.nrel.gov/pv/lcoe-calculator/.

NREL. 2018b "Levelized Cost of Energy Calculator." Energy Analysis. Accessed April 9, 2018. https://www.nrel.gov/analysis/tech-lcoe.html.

NREL. “Commercial PV - ATB.” Accessed October 14, 2019.

https://atb.nrel.gov/electricity/2017/index.html?t=sd.

NREL/Sandia/SunSpec Alliance SuNLaMP, and PV O\&M Working Group. Best Practices in Photovoltaic System Operations and Maintenance. NREL/TP-7A40-67553. December 2016. https://www.nrel.gov/docs/fy17osti/67553.pdf.

Lavappa, P.D.;Kneifel, J.D. Energy Price Indices and Discount Factors for Life-Cycle Cost Analysis, Annual Supplement to NIST Handbook 135 (ASHB 135). Accessed October 232019. https://nvlpubs.nist.gov/nistpubs/ir/2018/NIST.IR.85-3273-33.pdf

Shimura, Sergio, Rafael Herrero, Marcelo Knorich Zuffo, and Jose Aquiles Baesso Grimoni. "Production Costs Estimation in Photovoltaic Power Plants Using Reliability." Solar Energy 133 (August 2016): 294-304. https://doi.org/10.1016/j.solener.2016.03.070.

Wiser, R., Bolinger, M. and J. Seel. 2020. Benchmarking Utility-Scale PV Operational Expenses and Project Lifetimes: Results from a Survey of U.S. Solar Industry Professionals. Lawrence Berkeley National Laboratory. Correspondence with the author May 7, 2020. 